\title{
A democracia ao sul da América uma visão tocquevilleana
}

\author{
CLAUDIO VOUGA \\ A Inquisição jamais pôde impedir que circulas- \\ sem na Espanha livros contrários à religião \\ majoritária. O império da maioria faz coisa \\ melhor nos Estados Unidos; ele suprime até \\ mesmo a vontade de publicá-los.
}

(Tocqueville)

RESUMO: O artigo mostra como, na visão tocquevilleana, a democracia americana longe de ser um modelo é na verdade um caso particular. Apesar de sua erudição o nobre normando quase nada conhecia das instituições políticas do mundo ibérico, assim sendo para estudarmos a parte sul do continente americano de uma perspectiva inspirada em Tocqueville será o seu método e não suas análises empíricas que deverão servir de guia. A descrença nas instituições democráticas que encontramos hoje, de forma crescente, nos países da América ibérica nos desperta para a necessidade de aprofundarmos o estudo das instituições enraizadas em nossa tradição política e social. É provável que a descrença não seja na democracia mas num tipo determinado de variante de democracia que aparece aos povos da lbero-América como alheio a seu destino. Apesar dos votos piedosos de alguns cientistas políticos, em matéria de democracia, certamente, o que é bom para os Estados Unidos só é bom (se for) para os Estados Unidos.

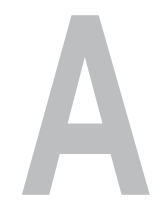

presente comunicação refere-se a um trabalho ainda em fase de projeto que pretende estudar as instituições políticas, as organi zações da sociedade civil e o autogoverno no Brasil. Acredito que um mesmo tipo de estudo é possível e desejável para outros países da América ibérica e então poderíamos comparar a versão portuguesa com a versão espanhola de nossa origem comum e verificar como

PALAVRAS-CHAVE: autogoverno, democracia, instituições políticas, Tocqueville, América do Sul.

Professor do Departamento de Ciência Política da FFLCH - USP 
Trabalho apresentado nas Primeiras Jornadas UBA/USP de Teoria Política em São Paulo, 14-15 de setembro de 2000. elas, diferindo entre si, diferem, e muito, da versão de democracia norteamericana de origem inglesa.

Pretendo utilizar-me daquilo que chamo de visão tocquevilleana pois foi esse autor quem primeiro percebeu por um lado a inelutabilidade da democracia nas sociedades modernas e por outro lado o perigo que a liberdade corre nessas mesmas sociedades. Esse olhar inquieto que o jovem Alexis lançava à América, tendo entretanto a França e sua revolução interminável como objetivo último, esse olhar, podemos também, hoje, lançar sobre nossos países.

Embora a democracia moderna entendida como exercício da liberdade em condições de máxima igualdade possível venha se tornando um valor universal, as formas de seu exercício são particulares a cada tempo e circunstância. A crise da democracia ainda in nuce mas que se afigura crescente e progressiva bem como o desencanto que a acompanha resultam em grande parte do esquecimento desse fato. $\mathrm{O}$ modelo de democracia norte americano não é exportável, ainda que fosse desejável; hoje em dia a democracia francesa, a democracia alemã, a democracia espanhola, a australiana ou mesmo a canadense dela são muito diferentes, por que então pretender que os países da América ibérica a tenham por paradigma? Isso não significa que estejamos condenados a governos autocráticos por sermos diferentes mas sim que inteiramente peculiar, de resto como mostra Tocqueville, são os Estados Unidos, e que a democracia ao sul da América, para ser sólida, tem de partir de nossos próprios território, clima, tradições, costumes, instituições políticas.

Apesar da imensa erudição de Tocqueville e de seu grande conhecimento das instituições do antigo regime europeu, bem como de seus numerosos escritos sobre a Inglaterra e Irlanda ou ainda sobre os territórios alemães, Prússia e Áustria ou mesmo Rússia, são praticamente inexistentes as referências à Espanha, quase só aparecendo em relação aos acontecimentos que tinham reflexos sobre a política externa desse país à época que Tocqueville era membro do parlamento ou mais tarde quando integrava o ministério Odilon Barrot na pasta dos negócios estrangeiros. Estranhamente uma das poucas referências às instituições políticas espanholas diz respeito ao espírito municipal e às instituições municipais e vai justamente no sentido contrário ao elogio feito pelo autor à força das instituições locais na América do Norte, sobretudo nas cidades da Nova Inglaterra. Referindo-se aos acontecimentos que vão se seguir à morte do rei Fernando VII e à guerra civil e desordens subseqüientes, diz Tocqueville:

O partido exaltado ou revolucionário existia sobretudo nas cidades, está mesmo hoje provado que só existia nas mesmas. Infelizmente o espírito municipal e as instituições municipais são tais na Espanha, e a capital exerce tão pouca influência, que a revolta pode se 
organizar em cada cidade. Esta organização municipal permitia aos revolucionários de achar facilmente, apesar de seu pequeno número, grandes e poderosos centros de ação nas grandes cidades que são numerosas na Espanha (Tocqueville, 1985, p. 357) ${ }^{1}$.

Entretanto, como comenta André Jardin em uma nota, esse e outros escritos de circunstância de Tocqueville em que é feita referência à Espanha não têm um embasamento muito firme sobre a evolução e a realidade desse país. Se quase nada existe na obra de nosso autor sobre a Espanha menos ainda sobre Portugal ou sobre sua ex-colônia americana.

Encontramos na obra de Tocqueville apenas umas poucas e vagas referências, na Democracia na América, ao México, aos espanhóis da América do Sul ou aos espanhóis e portugueses e suas ex-colônias, que servem sobretudo de contraponto e apoio para o seu raciocínio na análise das instituições anglo-americanas.

Depois de lamentar o estado de anarquia, guerra civil e despotismo em que América do Sul e México estão mergulhados Tocqueville quase desespera: quem poderá afirmar que as revoluções não sejam, em nosso tempo, o estado mais natural dos espanhóis da América do Sul? Nessa região, a sociedade se debate no fundo de um abismo de onde seus próprios esforços não são capazes de fazê-la sair.

O povo que habita essa bela metade de um hemisfério parece obstinadamente entretido em se rasgar as entranhas; nada pode desvia-lo disso. O cansaço o faz por um instante cair no repouso, e o repouso logo o conduz a novos furores. Quando considero esse estado alternativo de misérias e de crimes, sou tentado a crer que, no caso, o despotismo seria um benefício.

Mas estas duas palavras não poderão jamais achar-se unidas em meu pensamento (Tocqueville, 1981, p. 319).

Ou adiante no capítulo 10 da segunda parte do livro 1:

Os espanhóis e os portugueses fundaram na América do Sul grandes colônias que se tornaram mais tarde impérios. A guerra civil e o despotismo desolam hoje em dia essas vastas regiões (Tocqueville, 1981, p. 529).

Tocqueville, entretanto, nutre esperanças que no futuro essa região possa também vir a se constituir por nações bem regradas:

(...) a América do Sul é cristã como nós; tem nossas leis e nossos costumes, tem todos os germens de civilização que se desenvolveram no seio das nações européias e de seus descendentes; a América do Sul além do mais tem o nosso exemplo, por que permaneceria ela bárbara? (Tocqueville, 1981, livro I, p. 529).

1 Agradeço à generosidade intelectual de Marcelo Jasmin pela indicação da Question Espagnole onde se encontra o texto citado. 
Discípulo de Montesquieu, Tocqueville, como o barão de la Brède, sabe perfeitamente que modelos institucionais não atuam no vazio, independentemente de meio físico, clima, costumes etc. É o que ele nos diz no final do capítulo 9, da segunda parte do livro primeiro da Democracia na América:

Aqueles que, depois de lerem este livro, julgaram que escrevendo-o pretendi propor as leis e os costumes anglo-americanos à imitação de todos os povos que têm um estado social democrático, teriam cometido um grande erro; Ter-se-iam atido à forma, abandonando a substância de meu pensamento. Meu objetivo foi mostrar, através do exemplo da América, que as leis e sobretudo os costumes poderiam permitir a um povo democrático permanecer livre. De resto, estou muito longe de acreditar que deveríamos seguir o exemplo dado pela democracia americana e imitar os meios dos quais ela se serviu para atingir a finalidade de seus objetivos; pois não ignoro, de forma alguma, a influência exercida pela natureza do país e pelos fatos antecedentes sobre as constituições políticas e encararia como uma grande desgraça para o gênero humano que a liberdade devesse em todos os lugares produzir-se sob os mesmos traços (Tocqueville, 1981, livro I, p. 425)².

Não, a América e suas leis não são de forma alguma um modelo a ser seguido. Referindo-se especificamente ao México diz Tocqueville: Os habitantes do México, querendo estabelecer o sistema federativo, tomaram por modelo e copiaram quase inteiramente a constituição federal dos anglo-americanos seus vizinhos. Porém transportando para seu país a letra da lei, não puderam transportar ao mesmo tempo o espírito que a vivifica. Ví-mo-los portanto se embaraçarem nas engrenagens do governo duplo. A soberania dos Estados e a da União, saindo dos limites traçados pela constituição, penetram cada dia uma na outra. Ainda atualmente o México é conduzido da anarquia ao despotismo militar e do despotismo militar à anarquia (Tocqueville, 1981, livro I, p. 244).

Mas como vimos Tocqueville tem esperanças que a América do Sul seja capaz de como a Europa superar suas próprias trevas. Entretanto outro obstáculo se coloca:

(...) uma época mais ou menos distante virá sem dúvida na qual os Americanos do Sul formarão nações florescentes e esclarecidas.

${ }^{2}$ Grifos meus. Porém quando os espanhóis e os portugueses da 
América meridional começarem a experimentar as necessidades dos povos organizados, estarão ainda longe de poder satisfazê-las por si próprios; últimos rebentos da civilização, sofrerão a superioridade já adquirida pelos mais velhos. Serão por muito tempo agricultores antes de se tornarem manufatureiros e comerciantes e terão necessidade da intermediação dos estrangeiros para vender seus produtos além dos mares e obter em troca os objetos cuja necessidade nova se fará sentir.

Não tenhamos dúvidas de que os Americanos do Norte da América serão chamados um dia a prover as necessidades dos Americanos do Sul. (...)

Os Americanos dos Estados Unidos encontram-se diante dos povos da América do Sul precisamente na mesma situação que seus pais os Ingleses diante dos Italianos, dos Espanhóis, dos Portugueses e de todos os povos da Europa que, sendo menos avançados em civilização e em indústria, recebem daqueles a maior parte dos objetos de consumo (Tocqueville, 1981, livro I, p. 530).

Temos aqui o conde precursor da Teoria da Dependência ou será do Imperialismo?

Com o fim da União Soviética e a débacle das teorias políticas de inspiração socialista passou-se por um momento em que se pretendeu o fim da história, o fim da ideologia e, se não o fim, pelo menos a unicidade da teoria política. O velho homo economicus, desmoralizado na economia, porque, hélas, os agentes não se comportam racionalmente no mercado, de repente entra travestido pela porta dos fundos justamente no pensamento político, território tradicional das paixões. Reduzida a mercado, a política passa a ser apenas escolha racional e se ainda apresenta competição, como no processo eleitoral por exemplo, certamente o conflito parece eliminado e o poder, o centro mesmo de toda política e pensamento sobre a política, é dimensão inexistente. E por trás das escolhas, determinando tudo, num mundo em que se vive sem razão sem entretanto se morrer pela pátria ${ }^{3}$, está o bem estar econômico (That's the Economy, stupid $^{4}$ ). A Todo Poderosa Economia determinando as escolhas políticas como jamais poderia ter imaginado em seus piores momentos de paranóico devaneio nem mesmo o mais furioso dos marxistas vulgares.

Mas o século XX marca não só o fim da utopia socialista como também o fim da ingenuidade liberal apodada indevidamente de neo. O que todos os realistas em política, liberais ou não, sempre souberam é que o bom
${ }^{3}$ Referência aos versos da canção de Geraldo Vandré Pra não dizer que não falei de flores.

${ }^{4}$ Quem não se lembra da campanha eleitoral de Bush senior? 
funcionamento do mercado (garantia da propriedade, do cumprimento dos contratos etc.) tem como condição prévia a existência do Estado. O Leviatã é anterior à possibilidade de uma atividade econômica estável que permita ao homem a esperança de uma vida mais cômoda que, como sabemos, ao lado do medo da morte constituía para Hobbes a justificativa da abdicação da liberdade natural e constituição do pacto social.

Por razões que não cabe aqui discutir, muitas das quais certamente ainda não saíram da zona de sombra da proximidade histórica, nem a paz nem a prosperidade vingaram nesse processo que ainda estamos vivendo, de mundialização com hegemonia norte-americana. Se o socialismo acabou e o mercado reina, na verdade funciona com mão única para o fluxo de riquezas e no sul da América não estamos entre os privilegiados. Desgraçadamente nessa época de desilusões o perigo é que valores caros como a liberdade terminem indo pelo ralo com a irracionalidade do sistema capitalista comandado pelos Estados Unidos identificado indevidamente com a democracia.

Certamente é chegada a hora de pensar que Estado, que democracia queremos. É chegada a hora da Teoria Política. Ao lado das alternativas de modelo econômico, devemos pensar as variantes políticas possíveis dentro de um modelo econômico dominante. Quero dizer que, mesmo no capitalismo avançado, o modelo anglo-americano não é a única alternativa de democracia possível.

Hoje na América ibérica o espectro das ditaduras, militares ou não, começa a rondar nossos países: Peru, Colômbia, Equador, Venezuela, Paraguai. É necessário pensar que política queremos para implementar que tipo de sociedade. Ainda que as alternativas não sejam infinitas, ainda que como expressou Tocqueville estejamos presos num círculo fatal de onde não podemos sair, ainda assim temos escolha, ou nas palavras do conde " dentro de seus amplos limites, o homem é poderoso e livre, assim também os povos". E é, justamente, nesse espaço de liberdade que se desenrola a nobre arte da Política.

Tocqueville, ao estudar a América inglesa em meados do século passado, lançou as bases de uma reflexão sobre as sociedades democráticas, suas virtudes e seus horrores que parece hoje mais válida do que nunca. Por isso nossa proposta é a de lançar uma mirada tocquevilleana sobre a América portuguesa, sobre o Brasil.

Desde a publicação de sua obra, ou mesmo antes, desde a chegada de Tocqueville acompanhado de Beaumont, ao continente americano, são mal interpretadas, com boa ou má fé, suas idéias sobre os Estados Unidos, nos Estados Unidos. Longe de admitir a América inglesa como um modelo para a Europa, Tocqueville na verdade mostrava como era possível a eventualidade de manutenção da liberdade, mesmo quando a sociedade não tinha nem jamais tivera aristocracia como era o caso das antigas colônias, que se formam negando o passado e pretendendo refundar o mundo e o homem, contra a tradição, apenas baseando-se nas escrituras sagradas. Essa socie- 
dade que faz tábula rasa de tudo, guardadas as devidas distâncias, se assemelharia à Rússia do início da Revolução, ou ao Iram dos aiatolás. Não vou me estender sobre o horror da América na visão de nosso aristocrata, que na verdade pensava (gloso e interpreto): se até na América (isto é, USA) a liberdade pode subsistir então com mais facilidade onde a aristocracia moldou o mundo embora não mais existam as suas instituições políticas ela poderá vir a se manter.

III

Se, no Brasil, formos analisar nossas instituições políticas ou as organizações da sociedade civil ambas herdadas dos portugueses e as compararmos com as norte americanas estudadas por Tocqueville vemos uma clara vantagem para as nossas do ponto de vista imputável ao autor. Certamente a tradição de autonomia das câmaras portuguesas transplantadas para cá é pelo menos da mesma magnitude do que a das townships que tanto maravilharam o nobre francês. Também no que diz respeito às organizações da sociedade civil não eram pequenas igrejas ou associações que encontramos nestas terras meridionais porém instituições do porte das Misericórdias ou as Ordens Terceira que tiveram papel central tanto político como de welfare, social ou religioso, e que tem até hoje um papel destacado, isso sem contar toda a rede de associações que sempre perpassou vertical e horizontalmente a sociedade luso brasileira: irmandades, festeiros, dançadores, bandas e fanfarras, sociedades de artesãos vários e tantas outras que ainda subsistem com todo vigor.

Apenas partindo de uma leitura contemporânea de nossas tradições poderemos pensar a variante de democracia que é a nossa, porque compatível com o que fomos, com o que somos. Nossa democracia carece urgentemente de adjetivos.

Deixemos de lado por um momento o grande homem e pensemos no Brasil, enquanto não uma negação mas como uma continuidade do passado português, de resto como sempre se fez antes que as tendências jacobinas, infiltradas em uma certa historiografia recente, tivessem confundido a afirmação do próprio com a negação do passado.

É claro que é preciso, antes de mais nada, pensar as semelhanças e as diferenças da herança ibérica comum bem como a maneira como espanhóis e portugueses encararam seus novos territórios da América. Albert Hirschman em um ensaio sobre tema inteiramente diferente aponta aquela que certamente é a diferença fundamental das colonizações ibéricas.

No século XV, os reis católicos da Espanha concluíram, após séculos de luta, a reconquista de seu país, tirando-o do domínio muçulmano. No decorrer desse evento memorável, os governantes do reino imbuíramse de extraordinário fervor, zelo missionário e poder. 
Com a descoberta do Novo Mundo na América (o evento exógeno na história) esse espírito fervoroso encontrou um escoadouro pronto, inspirando a iminente conquista militar do novo continente e os subseqüentes esforços intensivos de proselitismo feitos pelo Estado e pela Igreja espanhola (Hirschman, 1996, p. 164).

Nada de semelhante passou-se nas terras ocupadas pelos portugueses onde não houve conquista militar nem proselitismo mas apenas feitorias no início ou depois cultivo voltado para o comércio. Dos portugueses aqui instalados herdamos duas coisas, uma sociedade civil extremamente forte e independente com características igualitárias embora não liberais. E, por outro lado, instituições políticas, vindas da Idade Média mas com características peculiares, como a força e independência das câmaras e o caráter popular da monarquia. Naturalmente as condições históricas singulares à formação de Portugal bem como a revolução de 1315 que, preservando a independência nacional, soldou uma aliança duradoura entre a coroa, setores da nobreza, comerciantes e populo minuto das cidades podem explicar muitas destas características que subsistiram da Idade Média até os tempos modernos, de resto extensamente tratadas pelos historiadores portugueses desde Herculano.

Com isso não pretendo, obviamente, ressuscitar a polêmica já superada de se houve ou não feudalismo no Brasil, certamente não houve, entretanto algumas instituições feudais em sua versão lusitana foram por nós herdadas, como também e sobretudo a cultura de um mundo aristocrático. Pretendemos mostrar que as instituições políticas de Portugal são transferidas e aclimatadas aqui e, sobretudo, que são os homens de um país que não está em decadência, muito pelo contrário, que para cá se deslocam numa saga nacional conformada ideologicamente pelo mundo aristocrático. Não muito tempo depois do início da ocupação das terras americanas, Portugal ele próprio perderia sua independência com a união de sua coroa à da Espanha sendo portanto difícil pensar-se, no início de nossa colonização, em um forte poder central como no caso da Espanha. Por outro lado as características da união das coroas garantiam a Portugal e colônias uma não ingerência direta por parte de Madri, no que resultava que a centralização característica da América espanhola também não operava nas terras que viriam a constituir o Brasil.

A tradição centralizadora e o caráter escravista da política e da economia brasileira são de tal forma enfatizados pelos estudos de história econômica e sociologia política que o outro lado, o governo local e a produção centrada no trabalho livre ou semi servil, tende a ser simplesmente posto de lado. Momento é chegado de deitar um olhar tocquevilleano a esse lado oculto da lua. Por exemplo deixar de enfatizar tanto o contraste com os Estados Unidos pois lá também encontramos colonização como empreitada estatal, vide Virgínia e Geórgia, e trabalho escravo. 
No Brasil não há nada de semelhante à Guerra civil norte-americana onde os vencedores impuseram algumas características de sua formação como o mito de origem de toda a nação: pequena propriedade, exploração familiar, trabalho assalariado, self government. Entretanto consideramos alguns episódios como:

- a Viradeira com a volta dos jesuítas, os grandes inimigos dos bandeirantes e de sua saga de expansão, essencialmente privada, com freqüência contra o poder central, agregando novas terras ao país;

- a necessidade de normalização do período da Regência e a luta contra as diversas tentativas separatistas ou federalistas;

- ou a derrota de São Paulo na Revolução Constitucionalista de 1932, que limou a aristocracia paulista da política nacional.

Podemos pensar que eles fizeram abafar toda uma tradição localista e anti estatista que tivemos na América portuguesa e no Brasil. Não quero, pelo menos por enquanto, dizer que ela seja dominante, apenas que ela existe e é escamoteada, ocultada. Cabe investigar as razões do eclipse.

Se o direito à diferença e conseqüentemente a garantia de não opressão das minorias é uma reivindicação dos liberais e dos libertários desde o século XIX e uma das bandeiras de luta contra os totalitarismos do século XX, quando pensamos em quais as grandes questões da democracia do século XXI algo de correlato imediatamente chama nossa atenção.

Queremos nos referir a um tema que, embora antigo, contemporaneamente, surge fora da esfera da reflexão política imediata, o tema da preservação da diversidade. O movimento ecológico há décadas vem mostrando como a diversidade é central para a preservação do equilíbrio de nosso planeta. Da mesma forma a diversidade das formas culturais, institucionais e organizacionais é fundamental para a preservação não só da liberdade como também da própria capacidade de inovação dos seres humanos, como já Stuart Mill tão vivamente nos mostra em seu famoso ensaio Sobre a liberdade.

Apesar de ser um tema para o qual, já na década de 30 do século XIX, também Tocqueville, com sua extraordinária capacidade premonitória, chamara a atenção, quando alertava para a tendência à mediocridade das sociedades democráticas, em grande parte ficou na sombra com o grande passo atrás que foi no século XX o surgimento e a consolidação dos regimes totalitários. A luta contra esses regimes mobilizou a atenção e a inventividade dos que refletiam então sobre a política. Tratava-se, por um lado, de lutar pela vitória militar ou ideológica da democracia sobre o totalitarismo e, por outro, pela implantação da democracia onde esta não existia, essa era a prioridade.

O tempo entretanto é chegado, se não quisermos cair no pesadelo tocquevilleano do despotismo gentil, de refletir seriamente sobre os males e fraquezas da democracia e na maneira de combatê-los Certamente um dos 
remédios que é prioritário é o da garantia da diversidade. Devo desde já esclarecer que não se trata, de modo algum, de uma defesa do multiculturalismo que na verdade é muito mais parte do problema do que a sua solução.

Com o fim dos regimes de economia de comando estatal e o conseqüente processo ao qual se chama de globalização, generalizou-se o pensamento de que um modelo formal de organização política, a democracia representativa, era o modo mais aperfeiçoado da gestão do governo das sociedades. Não quero discutir essa assertiva, digamos que possa ser correta para esse momento histórico da virada do século, embora graças em grande parte, entre outros, ao desenvolvimento da cibercomunicação já se possa pensar em formas exeqüíveis de democracia direta ou participativa que não poderiam ter sido devaneadas por Rousseau em seus solitários passeios.

Por enquanto entretanto, admitamos, não só que a democracia seja um valor universal, mas também que os rituais eleitorais, de constituição de maiorias e formação de governos, bem como as coreografias inter e intra poderes sejam, repito, no momento, os mais adequados para todos os estados constituídos e que os chamados direitos do homem sejam uma tábua de valores sobre a qual todos os povos são capazes de, em princípio, concordar.

Aí entretanto cessam as semelhanças entre as formas culturais, institucionais e organizacionais que presidem os diversos povos, países e nações, as unidades em que estes se subdividem bem como as associações, blocos ou confederações que existam ou venham a existir entre estes. Não se deve confundir, nem deixar que tentem nos confundir: os direitos humanos não são os direitos dos povos da Virgínia (apenas os brancos naturalmente pois para os negros apenas fica reservado esse direito desigual que é a ação afirmativa). E a democracia, valor universal, não são os lobbies no Congresso de Washington, ou o sistema que se pratica no Texas ou no Alabama entre os respectivos governadores e os capitólios estaduais.

Existe no norte de Portugal um ditado, muito lembrado no verão de 1975 quando alguns militares ingênuos, embora nefastos, tentavam impor à nação, a partir de Lisboa, um modelo de organização política rejeitado pela maioria da população, que diz: Para lá do Marão (da serra do Marão, que separa o Minho de Trás-os-Montes) mandam os que lá estão. Ou seja cada povo, cada comunidade, sabe quais as particularidades que mais lhe convém. Felizmente a sólida organização da sociedade civil portuguesa com sua tradição de autogoverno que remonta pelo menos à fundação da nacionalidade, foi capaz de resistir às campanhas de dinamização cultural com as quais a Quinta divisão do exército lusitano pretendia extirpar os aspectos considerados reacionários da cultura popular. Pretendia-se entre outras coisas proibir as touradas, o fado e o futebol, considerados reacionários. Até mesmo, sinal dos tempos, os horríveis seriados norte-americanos da televisão foram substituídos por inenarráveis enlatados e filmes soviéticos e da Europa central, que então era chamada do leste. 
Essa investida de alguns dos capitães de abril, na falhada conquista de mentes e corações, foi pouco mais que um sonho de algumas noites do verão quente de 1975 que não chegou a se tornar um pesadelo. Mas que dizer então, hoje, da ameaça da grande máquina igualizadora que quer aplastar as diferenças para fazer de todas as culturas, instituições e organizações meros reflexos, cópias a carbono, daquele que tem a pretensão de ser o modelo universal, mas que nada mais é do que o interesse particular de uma nação que tenta se fazer passar pelo interesse de todos. (Não será preciso aqui lembrar as análises de Marx ao mostrar como a ideologia burguesa pretende fazer passar seus interesses particulares de classe pelo interesse geral).

O processo de mundialização da democracia não pode ser um processo de submissão política de províncias à capital de um império que vive do blefe de que as conquistaria sem ser necessário deslocar suas legiões. Nem a abertura dos mercados, desejável em função da especialização e eficiência, deve ser uma via de mão única onde estranhamente vemos crise e desemprego em quase todos os países do mundo e apenas em um prosperidade e emprego. A Pérfida Albion ao menos deslocava a Royal Navy para recolher o botim que julgava ser- lhe devido.

E cabe justamente ao estado, cuja morte foi cedo decretada por aqueles que eram proprietários da agência funerária que lucraria com o enterro, garantir, contra os interesses alienígenas, contra a máquina globalizada de publicidade que pretende vender não só sanduíches, sodas e calçados bem como música, entretenimento e estilo de vida, a diversidade não só da música, do cinema, da literatura, das danças populares, das formas de organização da sociedade civil, da culinária (abaixo o fast food, viva o camarada Bové), da organização da família, dos valores religiosos, das associações festivas, esportivas ou outras, mas também, sobretudo, a diversidade das soluções para as questões postas por cada povo sobre a melhor maneira de se governar. Talvez houvesse um certo exagero quando um patriota da América ibérica se referia a nossos grandes irmãos do norte como inimigos do gênero humano, mas certamente será certo dizermos que com sua cruzada atual são certamente os inimigos da diversidade do gênero humano.

Finalizarei repetindo o mote de um poeta, mais bem sucedido, é verdade, em outros ramos da atividade humana: "Que cem flores desabrochem, que cem escolas rivalizem”.

Recebido para publicação em março/2001 
VOUGA, Cláudio. A democracia ao sul da América - uma visão tocquevilleana. Tempo Social; Rev. Sociol. USP, S. Paulo, 13(1): 117-128, maio de 2001.

KEY WORDS: self-government, democracy, political institutions, Tocqueville, South America.
VOUGA, Cláudio. Democracy south of America - a Tocquevillean perspective. Tempo Social; Rev. Sociol. USP, S. Paulo, 13(1): 117-128, May 2001.

ABSTRACT: This paper shows how, from a Tocquevillean point of view, the American democracy, far from being a model is, in reality, a unique case. In spite of his erudition, the noble Norman knew very little about the political institutions of the lberian world. Thus, to study the south of the American continent from a Tocquevillean inspired perspective, it is his method and not his empirical analysis that will be followed. The growing disbelief in democratic institutions in Iberian-American countries, nowadays, brings up the need to study in depth the institutions that are rooted in our political and social tradition. It is quite probable that the mistrust is placed not in democracy itself but in some specific kind of variant of democracy which appears to the Iberian-American population as alien to its destiny. In spite of the merciful wishes of some political scientists, when it comes to democracy, what is good for the United States is good only if it is for the United States.

\section{REFERÊNCIASBIBUOGRÁFICAS}

Hirschman, Albert . (1996) Autosubversão. São Paulo, Companhia das Letras.

Tocqueville, Alexis de. (1981) La démocratie en Amérique. Paris, Flammarion.

. (1985) Oeuvres complètes III. Ecrits et discours politiques. Paris, Galimard. 